\title{
Nearshore movement ecology of a medium-bodied shark, the creek whaler Carcharhinus fitzroyensis
}

\author{
Samantha EM Munroe ${ }^{1,2^{*}}$, Colin A Simpfendorfer ${ }^{2}$, James Moloney ${ }^{3}$ and Michelle R Heupel 2,4
}

\begin{abstract}
Background: The movement and habitat use patterns of medium-bodied nearshore sharks are poorly understood. However, these species face some of the highest levels of exposure to anthropogenic development. The habitat and space use strategies species exhibit affect their role within communities and how they respond to environmental change. The present study used passive acoustic telemetry to evaluate the residency, space use, and habitat use patterns of the creek whaler Carcharhinus fitzroyensis in a nearshore embayment in Queensland, Australia.

Results: Individuals were monitored for approximately 18 months. Half of the monitored population were highly resident to the bay. In contrast, several individuals spent less than 2 weeks in the bay, suggesting that broader movements may occur in a portion of the population. Size had no effect on residency. Activity space size varied between months and time of day but was also not affected by animal size. All C. fitzroyensis spent the majority of time in seagrass habitat (70\%) and deep water (>5 m) mud substrate (20\%). Shallow mudflat, sandy inshore, and reef habitats were rarely used (7\%). Although the sample size of immature individuals was relatively small, results indicated immature and mature C. fitzroyensis shared space and habitats.
\end{abstract}

Conclusions: Overall, C. fitzroyensis used a combination of nearshore movement patterns typically exhibited by small- and large-bodied species. The movement patterns exhibited by C. fitzroyensis suggest that this species has a moderately high degree of seagrass habitat specialisation. Seagrass habitat is typically highly productive and may be an important foraging habitat for this species. Given the consistent use of seagrass habitat, C. fitzroyensis are likely vulnerable to population decline as a result of seagrass habitat loss. Future research should continue to investigate the unique movements of medium-bodied sharks.

Keywords: Coast, Environmental change, Habitat selection, Kernel utilisation distributions, Nearshore, Residency, Medium-bodied sharks

\section{Background}

Nearshore areas are highly productive and dynamic environments that often contain a diverse range of habitat types, such as seagrass meadows, mangroves, and rocky and/or sandy substrate $[1,2]$. As a result of this productivity and diversity, nearshore areas function as important foraging and nursery grounds for many shark species

\footnotetext{
* Correspondence: samantha.munroe@my.jcu.edu.au

1AIMS@JCU, Australian Institute of Marine Science and College of Marine and Environmental Science, James Cook University, Townsville, QLD 4811, Australia

${ }^{2}$ Centre for Sustainable Tropical Fisheries and Aquaculture and the College of Marine and Environmental Science, James Cook University, Townsville, QLD 4811, Australia

Full list of author information is available at the end of the article
}

$[3,4]$. Unfortunately, nearshore ecosystem health and biodiversity is in a state of global decline $[5,6]$ due to numerous anthropogenic influences, including coastal pollution [7], inshore fishing [8], and climate change [9]. Consequently, there is a need to determine how environmental change in nearshore ecosystems affects shark species.

The majority of shark research in nearshore areas has investigated the habitat use of large-bodied species (maximum total length $>150 \mathrm{~cm}$ ) that use these areas as nursery grounds (for example, [10-12]). Nearshore areas provide juvenile sharks with protection from predators and in some cases productive foraging grounds [13,14]. As a result, juveniles of large-bodied species are often highly resident within nearshore areas (for example, [15]). Large-bodied 
adults use substantially larger amounts of space, spend more time offshore, and may only use specific nearshore areas for short periods of time for foraging or pupping $[16,17]$. In contrast, juveniles and adults of small-bodied coastal species (maximum total length $100 \mathrm{~cm}$ ), such as the Australian sharpnose shark Rhizoprionodon taylori and Atlantic sharpnose shark Rhizoprionodon terraenovae, use the same nearshore habitats simultaneously and are believed to have large coastal home ranges that include a wide array of habitats $[18,19]$.

Considerably less data is available on the nearshore habitat use of medium-bodied coastal species (maximum total length $150 \mathrm{~cm}$ ). As the life history characteristics of these species are sometimes an intermediate of those exhibited by large- and small-bodied species [20,21], medium-bodied coastal species may exhibit unique movement and space use patterns. For example, the mediumbodied spottail shark Carcharhinus sorrah exhibits high site fidelity to single nearshore embayments with individuals using small home ranges and consistent habitats [22], similar to large-bodied juvenile populations. However, at a population level, C. sorrah use a wide range of coastal habitats and juvenile and adult spottails are known to occupy the same coastal areas simultaneously [22,23].

The creek whaler Carcharhinus fitzroyensis is a mediumbodied coastal shark species endemic to northern Australia. Carcharhinus fitzroyensis most commonly inhabits turbid nearshore waters but has been caught at depths of up to $40 \mathrm{~m}$ [24]. Teleosts and crustaceans constitute the majority of its diet [20]. Size at birth is approximately $500 \mathrm{~mm}$ total length (TL); males mature at approximately $800 \mathrm{~mm}$ $\mathrm{TL}$ and females $900 \mathrm{~mm}$ TL; maximum size is approximately $1,350 \mathrm{~mm}$ TL $[20,25]$. Females give birth every year with one to seven pups per litter $($ mean $=3.7)$ [20]. Commercial inshore gillnet fisheries data indicates neonate $C$. fitzroyensis are found in intertidal zones moving into deeper waters as they grow [26]. However, little else is known about the movement and habitat use patterns of this species.

The purpose of this study was to define the movement and habitat use patterns of $C$. fitzroyensis in a nearshore area, compare movement strategies to sharks of other size categories, and evaluate its vulnerability to environmental change (that is, habitat decline or destruction). Passive acoustic telemetry was used to determine $C$. fitzroyensis residency, space use, habitat selection, and specialisation. Results of this study will lead to a better understanding of how C. fitzroyensis use nearshore habitats relative to other species and size classes.

\section{Results}

Sixteen C. fitzroyensis (3 male, 13 female) were caught and released with acoustic transmitters on the eastern side of Cleveland Bay between February and September
2012. Size ranged from 679 to $1,370 \mathrm{~mm}$ STL (mean \pm $\mathrm{SE}=943 \pm 48.9$ ). Five $C$. fitzroyensis were not detected or died following release and were excluded from analysis, as was one immature female that was recaptured and collected by a local commercial fisherman $36 \mathrm{~km}$ north of the original release location approximately 2 weeks after release. The remaining 10 C. fitzroyensis (1 male, 9 female) were monitored in Cleveland Bay from September 2012 to May 2014. Size, clasper length, and calcification indicated the male was immature, while seven females were mature and two were immature.

\section{Residency}

Presence in Cleveland Bay ranged by individual from 1 to 452 days (mean $\pm \mathrm{SE}=205 \pm 53$ ) (Figure 1). Three individuals left the array within 2 weeks of release and did not return within the monitoring period. The residency index of the sample population ranged from 0.002 to 0.74 (mean $\pm \mathrm{SE}=0.34 \pm 0.09$ ). There was no significant relationship between residency and size (ANCOVA, $F_{(1,18)}=0.1616, P>0.05$ ) or sample year (ANCOVA, $\left.F_{(1,18)}=0.1379, P>0.05\right)$. There was also no clear seasonal pattern in presence except for one mature female that was consistently present from September to December in 2012 and 2013, was briefly present in April 2013 and 2014, and was never detected between May and August during any year of the study.

Four mature female C. fitzroyensis were detected on receivers in Bowling Green Bay. These individuals were some of the most highly resident to Cleveland Bay. Two were only detected in Bowling Green Bay for single days before returning to Cleveland Bay. However, the two other females made brief excursions lasting approximately 1 week into Bowling Green Bay throughout the monitoring period.

\section{Space use}

With the exception of one individual, all resident individuals exclusively used the eastern side of Cleveland Bay. One mature female used both the east and west sides of the bay on a monthly basis, although this individual still spent the majority of time on the eastern side of the bay. Individual monthly activity space ranged from 2.6 to $19.8 \mathrm{~km}^{2}$ (mean $\pm \mathrm{SE}=10.6 \mathrm{~km}^{2} \pm 0.3$ ) for $50 \%$ KUDs and 9.1 to $81.9 \mathrm{~km}^{2}\left(\right.$ mean $\left.\pm \mathrm{SE}=47.9 \mathrm{~km}^{2} \pm 1.0\right)$ for $95 \%$ KUDs.

The model that best explained the distributions of both 50\% and 95\% KUD sizes included month and diel period as factors (Table 1). Shark length appeared to have little or no effect on KUD size, and the model that only included size as a factor was worse than the null for both 50\% and 95\% KUDs. KUD size was larger during the day than at night for both 50\% and 95\% KUDs (Figure 2). The influence of month on KUD size was 


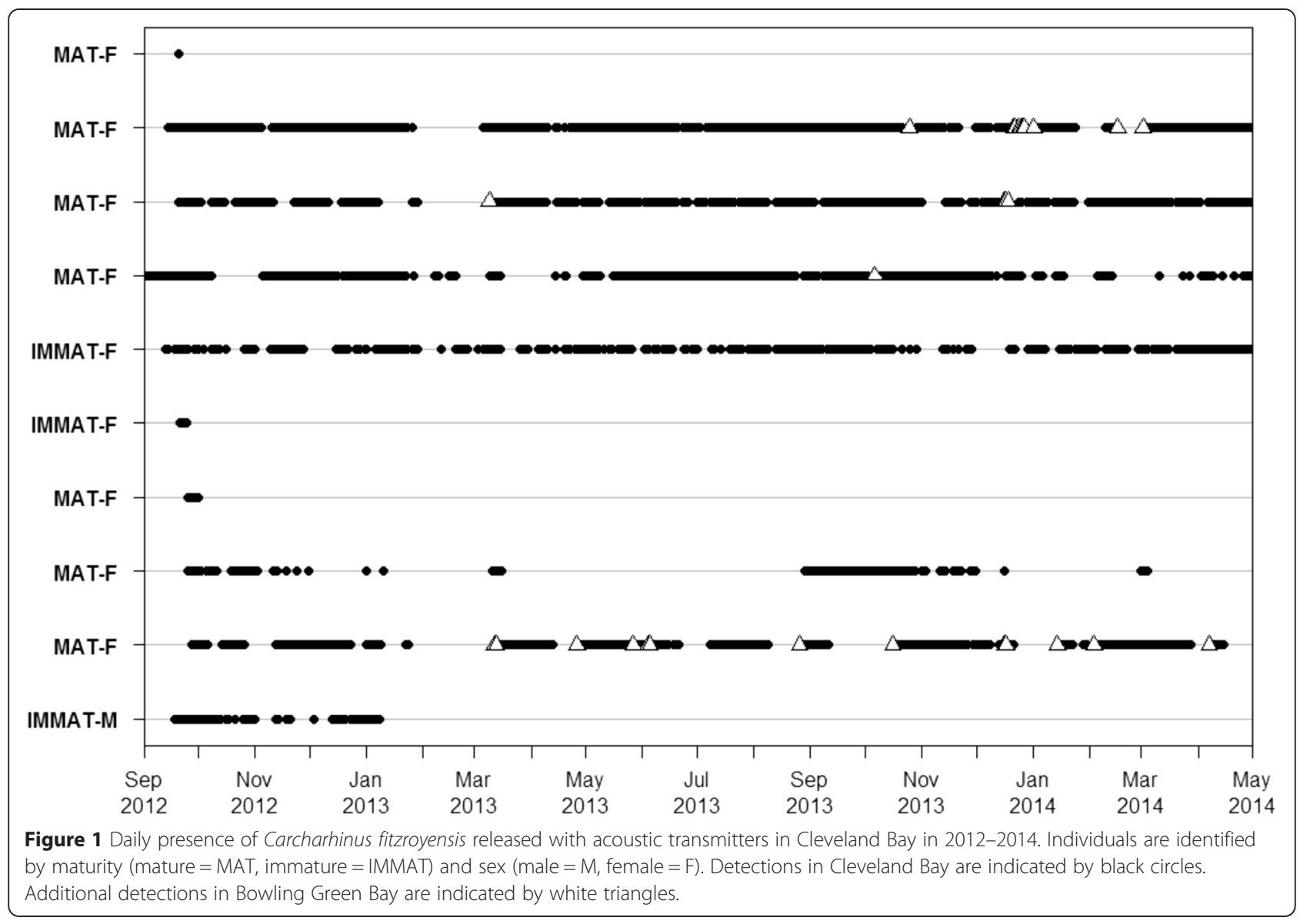

most prominent in May and August (Figure 3). In May, there was a distinct increase in 50\% and 95\% KUD sizes compared to all other months of the year. In contrast, August 50\% and 95\% KUD sizes were considerably smaller than those of all other months. KUD locations also fluctuated on a monthly basis according to this pattern. In August, activity space was centralised adjacent to the southeastern creek mouths in Cleveland Bay (Figure 4). During the rest of the year, but most notably in May,
KUD positions were more widely spread throughout the eastern half of the bay. The monthly pattern in KUD location was observed in immature and mature individuals.

\section{Habitat selection and specialisation}

Individuals were detected in all five habitat types; however, the majority of time was spent in seagrass habitats (Table 2). As there was no significant difference in time spent in each habitat between immature and mature

Table 1 Effect of animal size, month, and diel period on Carcharhinus fitzroyensis kernel utilisation distribution

\begin{tabular}{llllllll}
\hline Model & df & $\mathbf{5 0 \%}$ KUD AICc & 95\% KUD AICc & $\mathbf{5 0 \%}$ KUD $\boldsymbol{\Delta A I C c}$ & 95\% KUD AAICc & 50\% KUD weight & 95\% KUD weight \\
\hline KUD $\sim 1$ & 3 & $1,127.2$ & $1,624.2$ & 81.79 & 102.98 & 0.00 & 0.00 \\
KUD $\sim$ Size & 4 & $1,136.0$ & $1,631.4$ & 90.62 & 109.97 & 0.00 & 0.00 \\
KUD $\sim$ Size + Diel & 5 & $1,131.0$ & $1,624.2$ & 85.60 & 102.77 & 0.00 & 0.00 \\
KUD $\sim$ Size + Month & 15 & $1,064.3^{*}$ & $1,539.3^{*}$ & 18.91 & 17.93 & 0.00 & 0.00 \\
KUD $\sim$ Month & 14 & $1,054.3^{*}$ & $1,532.1^{*}$ & 8.87 & 10.72 & 0.012 & 0.05 \\
KUD $\sim$ Month + Diel & 15 & $1,045.4^{*}$ & $1,521.4^{*}$ & 0.00 & 0.00 & 0.982 & 0.969 \\
KUD $\sim$ Diel & 4 & $1,122.2^{*}$ & $1,617.2^{*}$ & 76.79 & 95.82 & 0.00 & 0.00 \\
KUD $\sim$ Size + Month + Diel & 16 & $1,055.4^{*}$ & $1,528.6^{*}$ & 10.02 & 7.19 & 0.007 & 0.027
\end{tabular}

Effect of animal size, month, and diel period on creek whaler Carcharhinus fitzroyensis 50\% and 95\% kernel utilisation distribution (KUD) size (km ${ }^{2}$ ). Degree of freedom (df), Akaike's information criterion correction (AICc), difference in AICc ( $\triangle \mathrm{AICC}$ ), and Akaike weight (weight) values are given for each model. AICc values are marked with an * if models were significantly different from the null model using a likelihood ratio test. The best fit models are italicised. 


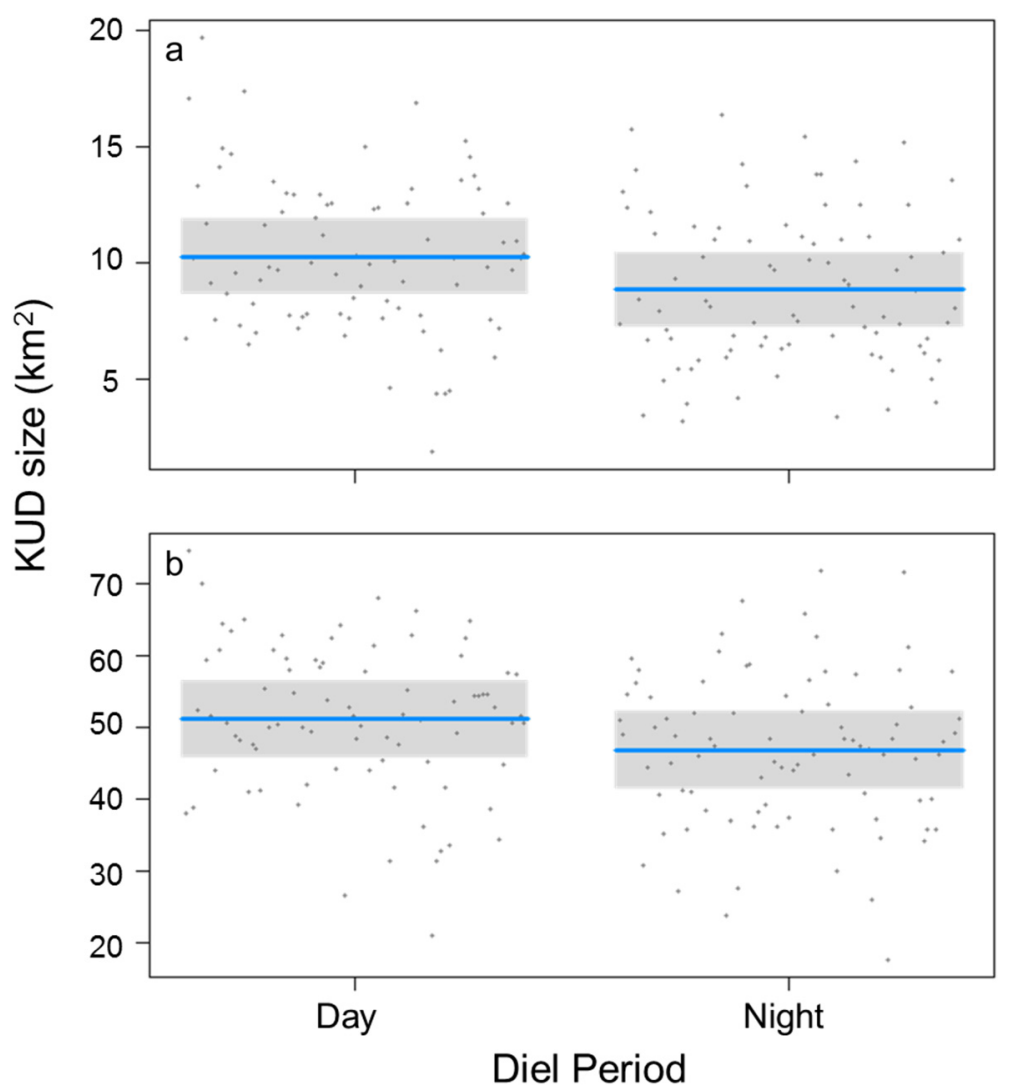

Figure 2 Effect of diel period on 50\% (a) and 95\% (b) kernel utilisation sizes ( $\mathrm{km}^{2}$ ) of Carcharhinus fitzroyensis. Blue bars are the mean predicted value, and grey bands are the $95 \%$ confidence intervals.

individuals (chi-squared test, $X_{16}^{2}=20.00, P>0.05$ ), all individuals were grouped for habitat selection and specialisation analysis. Mean individual Strauss selection values for the entire monitoring period indicated C. fitzroyensis selected seagrass habitat, used outer bay mud substrate opportunistically, and avoided reef, mudflat, and sandy inshore habitats (Figure 5). A chi-squared goodness-offit test indicated selection was significant $\left(X_{4}^{2}=144.758\right.$, $P<0.05)$. Mean fortnightly Strauss index values showed that selection of seagrass was consistently positive throughout the monitoring period (Figure 6). Selection of outer bay habitat was highly variable and fluctuated between high values of positive and negative selection. There was no apparent seasonal pattern in the selection of outer bay mud substrate; however, individuals selected outer bay habitat less often in the second year of the study. Mudflat, reef, and sandy inshore habitats were consistently avoided over time.

Mean individual niche breadth for C. fitzroyensis was moderate and ranged from 0.70 to 0.77 (mean $\pm \mathrm{SE}=$ $0.73 \pm 0.03$ ). Mean individual niche overlap was large and ranged from 0.91 to 1 (mean $\pm \mathrm{SE}=0.97 \pm 0.03$ ), indicating resident $C$. fitzroyensis used nearly identical proportions of the same habitats.

\section{Discussion}

The residency, space use, and habitat use patterns exhibited by $C$. fitzroyensis suggest that this species has a moderately high degree of habitat specialisation in nearshore environments. High individual niche overlap and consistent habitat selection patterns exhibited by the population show that there was limited individual variability in habitat use. All resident individuals, regardless of age class, almost exclusively used seagrass habitats and to a lesser extent outer bay mud substrate habitats. Although the small sample size of immature individuals has limited our ability to compare the habitat and space use of age classes, the shared use of nearshore areas by mature and immature C. fitzroyensis is consistent with other small- and medium-bodied coastal species, such as $R$. acutus [24], R. terraenovae [18], R. taylori [19], C. sorrah [21], and the grey-smooth hound shark Mustelus californicus [27,28]. However, in contrast to C. fitzroyensis, many smallbodied coastal species use a wide array of habitats. For example, $R$. taylori, $R$. terraenovae, and $M$. californicus all exhibited low residency to single nearshore areas $[18,19,27]$. $R$. taylori and $R$. terraenovae also used a variety of habitats in nearshore embayments $[18,19]$. Although $C$. sorrah displayed high residency and site fidelity to single 


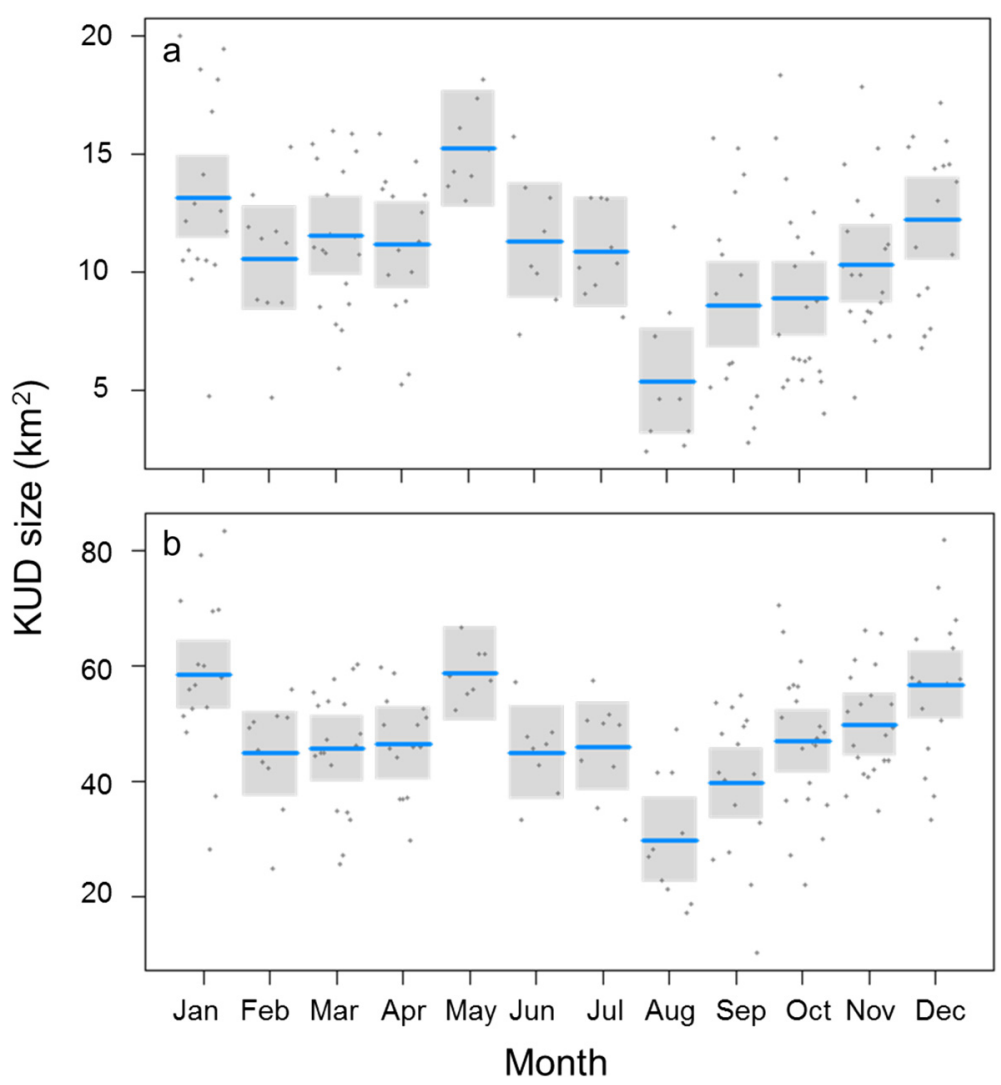

Figure 3 Effect of month on 50\% (a) and 95\% (b) kernel utilisation sizes $\left(\mathrm{km}^{2}\right)$ of Carcharhinus fitzroyensis. Blue bars are the mean predicted value, and grey bands are the $95 \%$ confidence intervals.

nearshore habitats, individuals also demonstrated a high degree of spatial segregation and individual variability in habitat use [22,29]. Unlike C. fitzroyensis, C. sorrah demonstrated no habitat preference at the population level. Instead, the residency and habitat use patterns exhibited by C. fitzroyensis are more similar to those exhibited by juveniles of large-bodied species. Juveniles of large-bodied species, such as the pigeye shark Carcharhinus amboinensis, the bull shark Carcharhinus leucas, and the lemon shark Negaprion brevirostris, are highly resident to nearshore areas and often use the same habitats and home ranges for long periods of time [15,30,31]. Therefore, the results of this study demonstrate that $C$. fitzroyensis used a combination of movement strategies previously reported in small- and large-bodied species.

It has been suggested that small-bodied coastal species adopt more mobile, less specialised space use strategies because it allows them to take advantage of a wider array of habitats [19]. However, long-term use of seagrass suggests that this habitat had sufficient resources to support the majority of the medium-bodied C. fitzroyensis population over long periods of time. Consistent use of nursery areas by large-bodied sharks is in part motivated by high nearshore productivity and prey availability [32] but see $[33,34]$ for exceptions. Seagrass habitats are usually highly productive and contain relatively large populations of small fish and bottom-dwelling prey [35-37]. Therefore, seagrass habitat may be excellent foraging grounds for C. fitzroyensis. Moreover, consistent use of seagrass habitat on the eastern side of Cleveland Bay could result in greater familiarity with the distribution of resources in that area and thus greater prey capture success [38,39]. Therefore, increased resource availability and better knowledge of resource distribution could make it highly beneficial for $C$. fitzroyensis to remain in the eastern side of the bay over long periods of time. The affinity for seagrass and the eastern side of Cleveland Bay may have also been due to the large rivers and creeks that drain into this area. Carcharhinus fitzroyensis are known to use rivers and freshwater areas ([40], Adkins, unpublished data), and catch and acoustic data suggest that young of the year C. fitzroyensis occupy areas close to shore and near river mouths ([26], Munroe, unpublished data). However, the extent to which $C$. fitzroyensis use freshwater habitats and why is unclear, and more work is needed to determine how the presence of freshwater outlets influences habitat selection. It should be noted that some of the highly resident $C$. fitzroyensis made occasional 

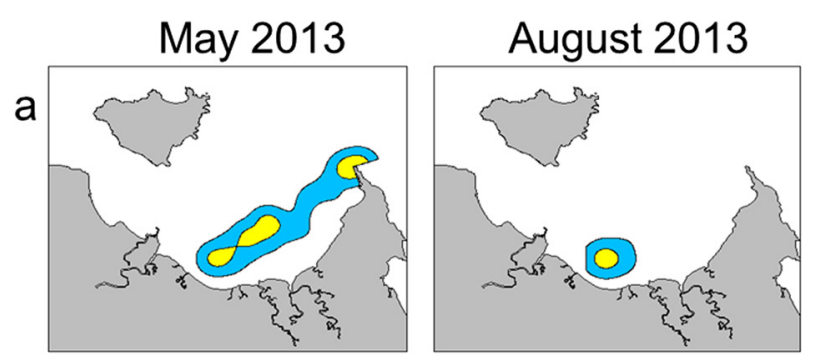

December 2013
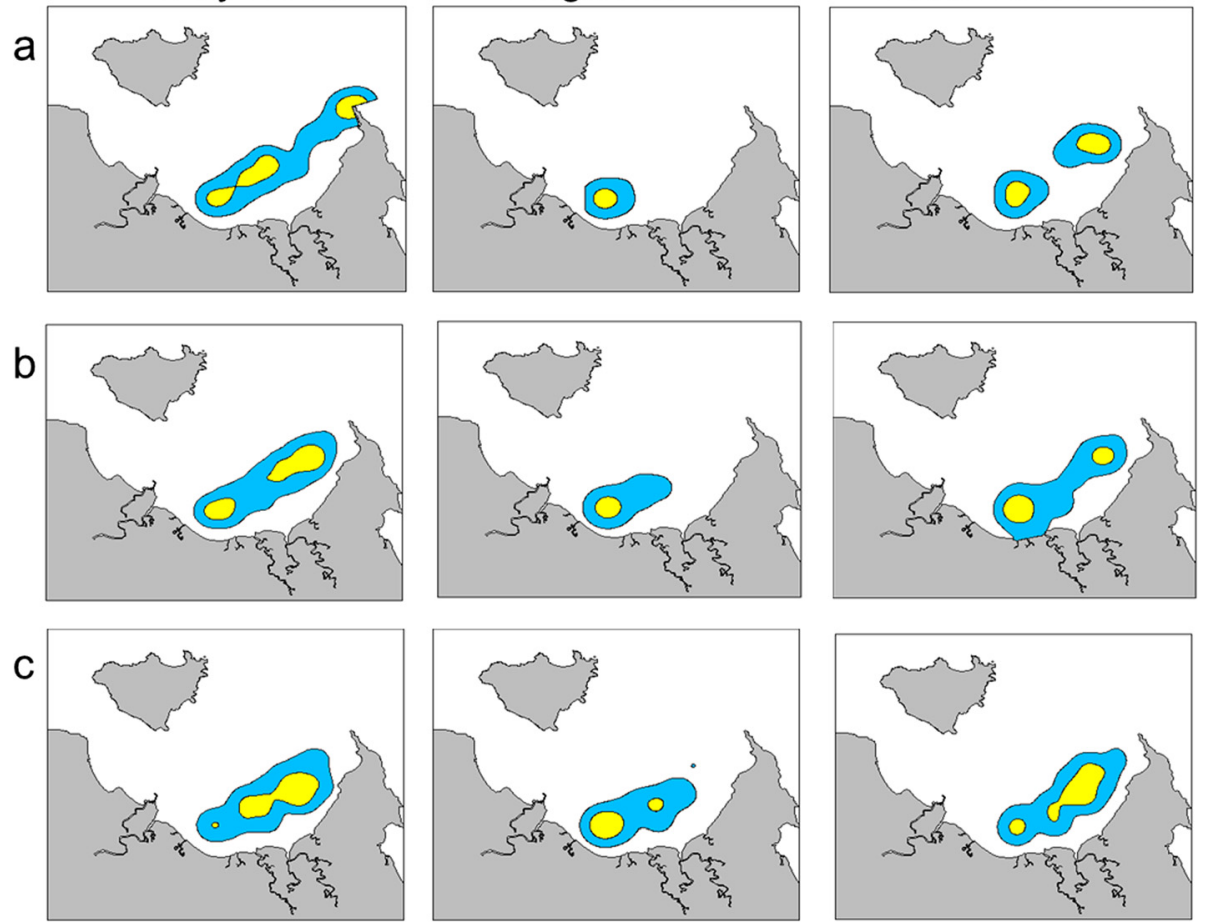

Figure 4 Monthly activity spaces of one immature (a) and two mature (b, c) Carcharhinus fitzroyensis in Cleveland Bay in May 2013, August 2013, and December 2013. Each panel shows the 95\% (blue fill) and 50\% (yellow fill) kernel utilisation distributions.

excursions into Bowling Green Bay and the habitats used during those excursions could not be precisely determined. However, Bowling Green Bay is dominated by mud substrate and seagrass habitats $[41,42]$. Therefore, when individuals were in Bowling Green Bay, it is likely that they were utilising habitats similar to those used in Cleveland Bay.

It is possible that the close association with seagrass habitat and the eastern half of the bay demonstrated by $C$. fitzroyensis was due to bias in catch distribution. Given that all C. fitzroyensis individuals were caught on the eastern half of the bay, the high residency to that area may have been the by-product of where individuals were captured.

Table 2 Time spent in each habitat by mature and immature Carcharhinus fitzroyensis in Cleveland Bay

\begin{tabular}{lll}
\hline Habitat type & $\begin{array}{l}\text { Time spent (\%) } \pm \\
\text { SE (mature) }\end{array}$ & $\begin{array}{l}\text { Time spent (\%) } \pm \\
\text { SE (immature) }\end{array}$ \\
\hline Seagrass & $72.9 \pm 3.5$ & $72.7 \pm 6.26$ \\
Outer bay mud substrate & $20.4 \pm 4.4$ & $20.0 \pm 2.7$ \\
Reef & $0.09 \pm 0.1$ & $0.0 \pm 0.0$ \\
Sandy inshore & $1.6 \pm 1.2$ & $0.19 \pm 0.19$ \\
Intertidal mudflat & $5.0 \pm 2.5$ & $7.11 \pm 3.69$ \\
\hline
\end{tabular}

Mean and standard deviation of time spent in each habitat by mature and immature Carcharhinus fitzroyensis in Cleveland Bay, measured as a percent with standard error (SE).
However, fishery-independent and fishery-dependent sampling throughout Cleveland Bay demonstrated that C. fitzroyensis was almost exclusively captured on the eastern side of the bay (Simpfendorfer, unpublished data) and was never captured in reef habitat [43]. Therefore, habitat use and activity space data are likely representative of how this species uses space within Cleveland Bay and are not the result of sampling bias. Fishery-independent catch data from northern Australia also showed that this species is often caught in mud substrate habitats and/or in areas with high potential for benthic growth ([41], Simpfendorfer, unpublished data). Therefore, results from coastal catch data support the conclusion that seagrass is one of the primary habitats used by $C$. fitzroyensis.

While seagrass habitat was the principal habitat used by $C$. fitzroyensis, moderate habitat specialisation values and selection analysis indicate seagrass habitat was used in conjunction with outer bay mud substrate. Use of outer bay mud substrate was highly variable over time, and lack of seasonality in selection suggests that this habitat was not used in response to seasonal abiotic changes in the environment. Selection of outer bay habitat could represent occasional foraging excursions in this habitat. Although outer bay habitats were available on both sides of Cleveland Bay, C. fitzroyensis rarely used outer bay habitats on the western side of the bay. This would 


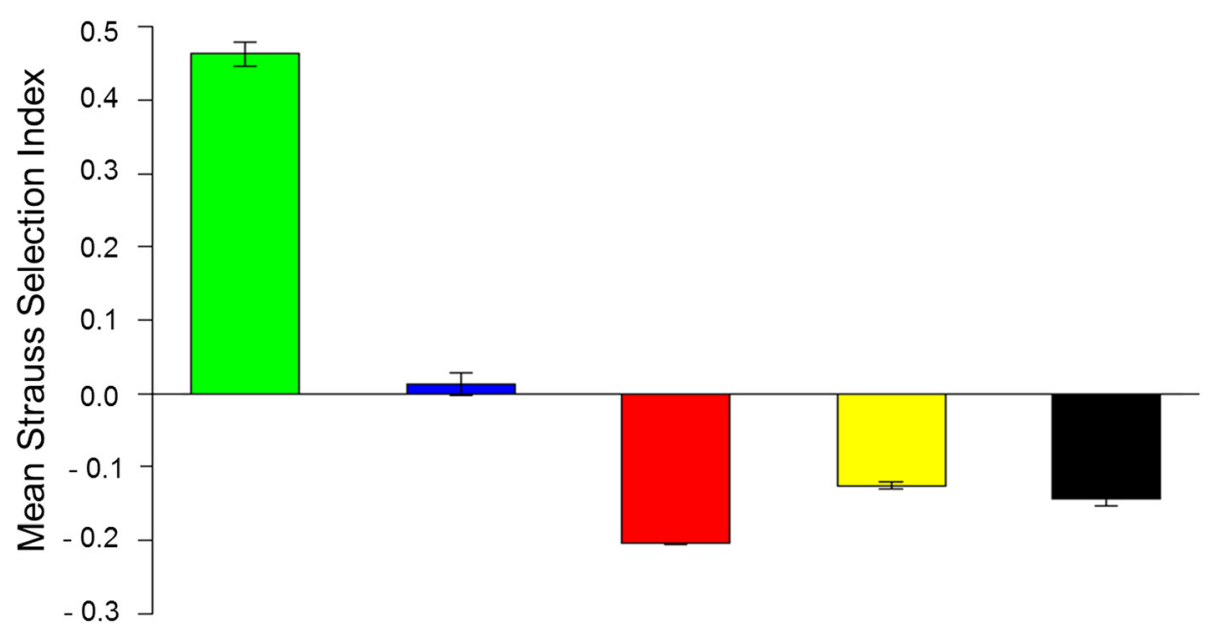

Figure 5 Mean Strauss linear habitat selection index values of potential seagrass (green), outer bay mud substrate (blue), reef (red), sandy inshore (yellow), and mudflat (black) habitats by Carcharhinus fitzroyensis in Cleveland Bay between September 2012 and May 2014 . Bars indicate the standard error.

suggest that, regardless of why outer bay habitat was used, individuals preferred to remain in close proximity to seagrass habitat. Consistent avoidance of sandy inshore, reef, and mudflat habitat suggests that these habitats were not suitable for C. fitzroyensis. Avoidance of mudflat habitat may be the result of ontogenetic segregation within the species. As previously discussed, there is some evidence to suggest that YOY C. fitzroyensis use shallow mudflat habitats, potentially for protection from predators [44]. However, more information is needed to determine why $C$. fitzroyensis avoided these habitats.

Residency data demonstrated that there was individual variability in presence. Several individuals spent less than
2 weeks in the bay, suggesting that broader movements occur in a portion of the population. Further evidence of broad movement came from an individual that was recaptured $36 \mathrm{~km}$ from Cleveland Bay a few weeks after its release. Individual variability in presence has been reported in other elasmobranchs, such as the mediumbodied $C$. sorrah [22] and the cownose ray Rhinoptera bonasus [45]. It is possible that some $C$. fitzroyensis individuals may have used more transitory strategies to gain greater access to a wider range of resources, such as prey and potential mates [22].

The space use patterns exhibited by resident $C$. fitzroyensis may have also been motivated by prey availability.

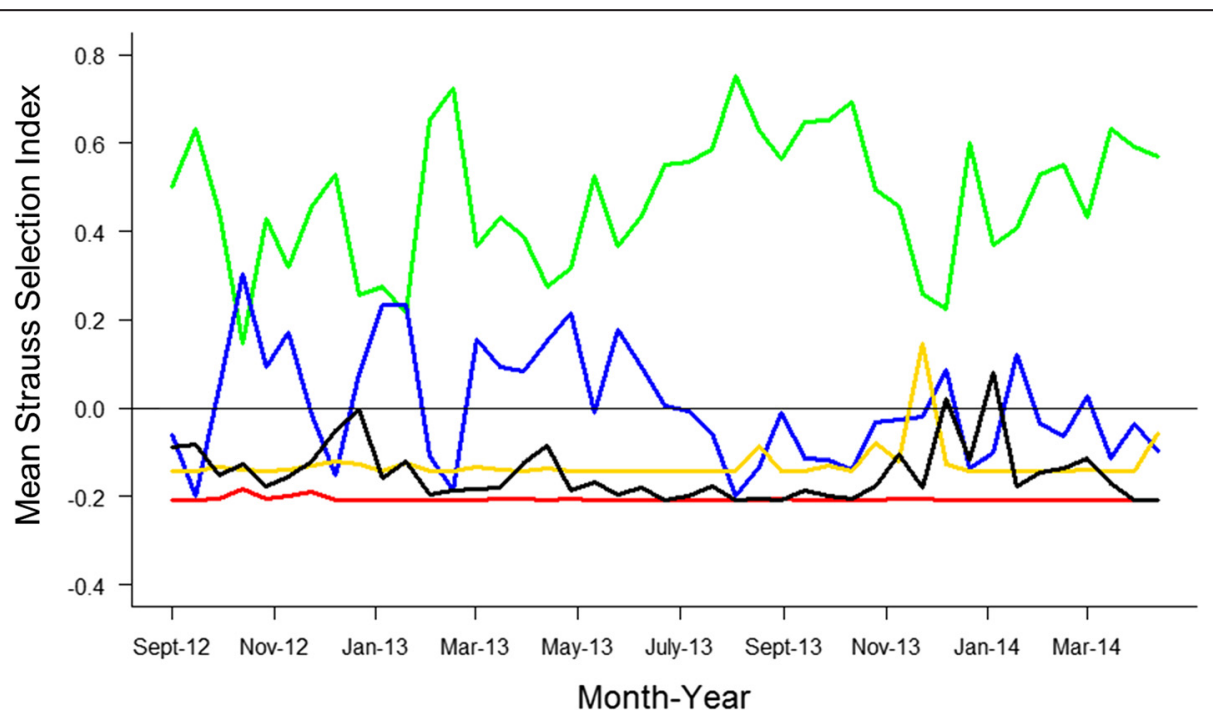

Figure 6 Mean fortnightly individual Strauss linear selection values of Carcharhinus fitzroyensis in Cleveland Bay for seagrass (green line), sand (yellow line), outer bay mud substrate (blue line), intertidal mudflat (black line), and reef (red line). 
The short-term change in activity space and location observed in August and May was concurrently observed in blacktip sharks, Carcharhinus tilstoni and Carcharhinus limbatus, in Cleveland Bay (Munroe et al., unpublished data). The simultaneous movement of both populations to the southeastern corner of the bay suggests that an external biotic or environmental stimulus caused changes in population distribution. As this population spent the majority of time in seagrass habitat, it was originally hypothesised that changes in seagrass productivity may have been responsible for changes in movement. However, there is no data to indicate there was a sudden change in seagrass distribution in August 2013 compared to previous months [46], suggesting that potential changes in seagrass density and distribution were not a significant influence on the changes in $C$. fitzroyensis space use at that time. If $C$. fitzroyensis were responding to changes in abiotic factors (for example, temperature, salinity), changes in space use would likely mimic the more gradual pattern of changes in bay temperature and salinity. However, the changes in movement patterns demonstrated by $C$. fitzroyensis were highly punctuated. Therefore, it appears more likely that the short-term change in space use by $C$. fitzroyensis may have been a response to a short-lived biotic factor, such as a change in prey location and abundance. Diel patterns in space use may also be linked to foraging behaviour. Larger daytime activity spaces suggest that $C$. fitzroyensis were more active during the day and may be primarily diurnal feeders. This contrasts with what has been found in other elasmobranchs that typically utilise small core areas during the day and move more widely at night for feeding [47-49].

\section{Conclusions}

The results of this study have shown that $C$. fitzroyensis exhibited habitat and movement strategies that are often associated with both small- and large-bodied species. While immature and mature age classes shared space and habitats and some individuals exhibited low residency to the bay, portions of the population were highly resident and specialised to seagrass habitat. While the consistent use of a single habitat can be highly beneficial, for example it can result in increased familiarity with resource distribution, this strategy could also make $C$. fitzroyensis more vulnerable to environmental change, specifically to the deterioration of seagrass habitat. Seagrass habitat abundance and biodiversity is under threat of decline from numerous human activities, including dredging [50,51], excessive nutrient deposition [52,53], chemical contamination such as herbicides [54], and the effects of climate change [55-57]. As immature and mature medium-bodied individuals share space and resources, declines in seagrass availability would likely affect all age classes within the population. Results of this study also suggest that medium-bodied coastal species may use nearshore habitats differently compared to other size classes of sharks. Therefore, future research should strive to increase understanding of mediumbodied species and the ecological causes, costs, and benefits of their behaviours.

\section{Methods}

\section{Ethics statement}

All research was conducted in accordance with James Cook University (JCU) animal ethics permit A1566 and Great Barrier Reef (G11/346181.1) and DEEDI (144482) permits for animal collection. This research was approved by the JCU ethics committee and relevant state authorities. Animals were handled quickly to ensure a high chance of survival following release. Sharks were kept in an on-board water tank with flowing water during surgery. No additional samples were taken during processing.

\section{Study site}

Individuals were monitored in Cleveland Bay, Queensland, Australia, a shallow embayment on the northeast coast of Australia (Figure 7). Cleveland Bay covers an area of approximately $225 \mathrm{~km}^{2}$ and is $27 \mathrm{~km}$ wide. The majority of the bay has a depth of less than $10 \mathrm{~m}$ and a maximum tidal range of $4.2 \mathrm{~m}$. The majority bottomtype is soft mud substrate and to a lesser extent sandy substrate. The bay also contains seagrass patches (Cymodocea serrulata, Halophila spp., Halodule uninervis) and coastal reefs. Mangroves line the southern shore of the bay. The main river outlets are on the southeastern side of the bay and are adjacent to intertidal mudflats and seagrass habitat.

Sixty-three VR2W acoustic receivers (Vemco Ltd., Bedford, Canada) were installed inside Cleveland Bay to monitor C. fitzroyensis movements. The receivers were installed in the primary habitat types within the bay, specifically intertidal mudflats, outer bay mud substrate $(>5$ $m$ depth), sandy inshore substrate, reefs, and seagrass. Data were downloaded from the receivers every 3 months. The Australian Institute of Marine Science (AIMS) deployed nine additional receivers in Bowling Green Bay adjacent to the south of Cleveland Bay. Most of these receivers were installed between depths of 9.2 to $11.0 \mathrm{~m}$ with mud substrate. Therefore, they were classified as outer bay mud substrate receivers, but data from these receivers were not included in residency, space use, or habitat use analysis.

\section{Field methods}

Sharks were captured using 200-m-long 11.45-cm-mesh gillnets, bottom-set 400-m long-lines, and baited rod and reel. Long-lines were made of 6-mm nylon mainline that was anchored at both ends. Gangions were made of 


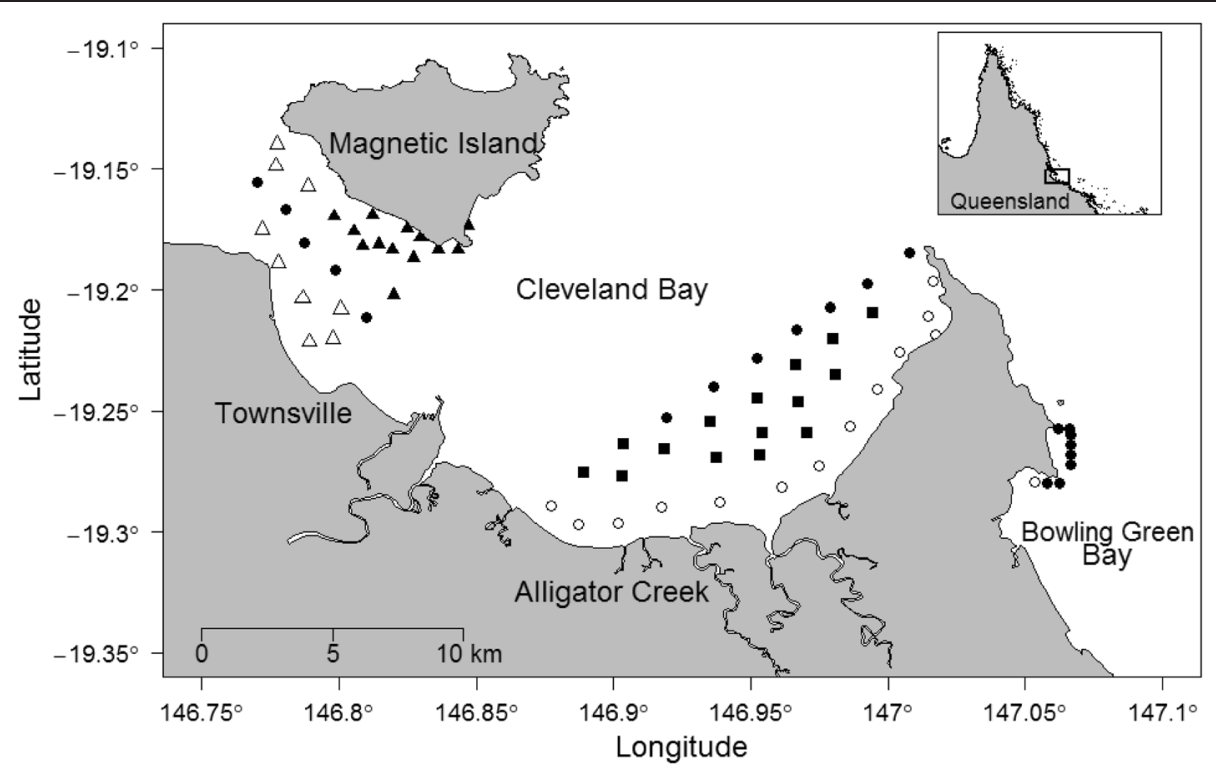

Figure 7 Locations of acoustic receivers in intertidal mudflat (white circle), seagrass (black square), outer bay mud substrate (black circle), inshore sand (white triangle), and reef habitat (black triangle) in Cleveland Bay, Queensland, Australia.

$1 \mathrm{~m}$ of $1.5-\mathrm{mm}$ wire leader and $1 \mathrm{~m}$ of $4-\mathrm{mm}$ nylon cord. Fifty to 70 size 14/0 Mustad tuna circle hooks (O. Mustad \& Sons A.S., Gjövik, Norway) were used per long-line and baited with butterfly bream (Nemipterus sp.), squid (Loligo sp.), blue threadfin (Eleutheronema tetradactylum), or mullet (Mugil cephalus). Gillnets were set for 15 to $20 \mathrm{~min}$, while long-lines were set for 45 to $60 \mathrm{~min}$.

Individuals were fitted with V16 acoustic transmitters (Vemco Ltd., Bedford, Canada). To ensure long-term retention, the transmitters were implanted into the body cavity. Absorbable sutures were used to close the incision. Individuals were tagged with an individually numbered Rototag (Daltons, Henley-on-Thames, England) in the first dorsal fin, measured to the nearest millimetre stretch total length (STL), sexed, and released. The transmitters emitted a unique code at $69 \mathrm{kHz}$. Unique transmitter codes allowed for the identification of individuals. To prevent acoustic signals from overlapping, the transmitters pulsed on a random repeat interval of 45 to $75 \mathrm{~s}$. Range testing analysis found that transmitters had a maximum detection range of $900 \mathrm{~m}$ based on 0.05 probability of detection [58]. Range testing analysis was conducted in each habitat type and found that the maximum detection range was similar throughout the bay.

Detection data were reviewed for false detections. Detections were determined to be false if 1 ) there were less than two detections per receiver per day, 2) detections were recorded on different receivers separated by large distances (for example, opposite sides of the bay) over short periods of time, 3) an individual was consistently and exclusively detected on a single receiver for long periods of time (that is, individual died), or 4) detections were recorded after the scheduled end of the life of the transmitter. All false detections were removed from data sets prior to analysis.

\section{Statistical methods Residency}

Presence was evaluated each day, with individuals deemed present if they were detected 2 or more times in the array in a given day. Residency was determined using a residency index that calculated the number of days an individual was present in the array as a proportion of the total days monitored $[59,60]$. The index ranged from 1 to 0 , indicating high to low residency, respectively. An ANCOVA was used to test for differences in residency between sample years with STL as a covariate. Individuals that were present in the bay for less than 2 weeks were excluded from space use and habitat analysis.

\section{Space use}

Individual positions were estimated using a mean position algorithm to determine individual centre of activity (COA) locations [61]. The COA represented a weighted mean position for each 30-min interval an individual was detected in the array. COA locations were used to calculate individual monthly activity space as $50 \%$ and 95\% kernel utilisation distributions (KUDs) using the adehabitatHR package in R version 3.0 [62]. To prevent overestimation of KUD size, KUD calculations incorporated an impassable boundary that represented the Cleveland 
Bay coastline. KUD calculations used a smoothing parameter of 0.008. A linear mixed effects model was used to determine if 50\% and 95\% KUD sizes were affected by animal size, month, and/or diel period. To account for repeated measures in the data, individual was incorporated as a random factor in the resultant models. Models were computed using the nlme package in R [63]. Models were compared using Akaike's information criterion with a small sample size bias correction (AICc) where models with the lowest AICc were considered to be the most significant drivers of KUD size. Akaike weights were also calculated to facilitate model assessment [64].

\section{Habitat selection}

Cleveland Bay was divided into regions based on the distribution of five distinct habitat types: intertidal mudflats, outer bay mud substrate ( $>5 \mathrm{~m}$ depth), sandy inshore substrate, reefs, and seagrass. Receivers were assigned a habitat type based on their location in the bay. Habitat availability was determined by calculating the proportion of total receivers in the array represented by each habitat. Proportional habitat use by individuals was determined by comparing the amount of time spent in a habitat to the total amount of time spent in the array.

The proportion of time individuals spent in each habitat was compared to habitat availability using [65] linear selectivity index $(L i)$ to determine if $C$. fitzroyensis were selecting or avoiding habitats:

$$
L_{i}=r_{i}-p_{i}
$$

where $r_{i}$ was the proportion of habitat $i$ used and $p_{i}$ was the proportion of habitat $i$ available in the study site. $L_{i}<0$ indicated negative selection or avoidance. $L_{i}>0$ indicated positive selection. $L_{i}=0$ indicated the habitat was neither positively nor negatively selected and was used opportunistically [65]. The mean of resident individual $L_{i}$ values was calculated for each year and each 2-week time period within each year to assess population habitat selection over time. A chi-squared goodness-of-fit test was used to determine if the proportion of time the resident population spent in each habitat was significantly different from habitat availability and hence if mean annual selection was significant.

\section{Habitat niche breadth}

Niche breadth of resident individuals was measured using Hutchinson's niche definition which only included the habitats a species used and in what proportions they used those habitats $[66,67]$. Based on this definition, a modified Freeman-Tukey statistic was used to calculate population niche breadth [68]:

$$
\mathrm{FT}=\sum_{i=1}^{R}\left(p_{i} q_{i}\right)^{1 / 2}
$$

where $p_{i}$ was the proportion of habitat $i$ used, $q_{i}$ was the proportion of habitat $i$ available in the study site, and $R$ was the total number of habitats available. The output ranged from 0 , which indicated a narrow niche and a highly specialised species, to 1 , which indicated a large niche. A variation of Equation 2 was used to calculate individual niche overlap [69]:

$$
\mathrm{FT}=\sum_{i=1}^{R}\left(p_{i k} p_{j k}\right)^{1 / 2}
$$

where $p_{i k}$ and $p_{j k}$ were the proportions of habitat $R$ used by individual $i$ and $j$, respectively. The output similarly ranged from 0 to 1 . A value of 0 indicated no overlap in habitat niche breadth between a given pair of individuals and 1 indicated complete overlap in habitat niche breadth between a given pair of individuals. Where applicable, all data were checked for normality using normality and homogeneity of variance diagnostics in $\mathrm{R}$ version 3.0 ( $\mathrm{R}$ Development Core Team: www.r-project.org) and data were $\log 10$ transformed if necessary.

\section{Abbreviations}

$\triangle A I C c$ : difference in bias-corrected Akaike's information criterion between a given model and the best model; AlCc: bias-corrected Akaike's information criterion; AIMS: Australian Institute of Marine Science; COA: centre of activity (the COA represented a weighted mean position for each 30-min interval an individual was detected in the array); F: female C. fitzroyensis; IMMAT: immature C. fitzroyensis; KUD: kernel utilisation distribution; M: male C. fitzroyensis; MAT: mature C. fitzroyensis; SE: standard error; STL: stretch total length.

\section{Competing interests}

The authors declare that they have no competing interests.

\section{Authors' contributions}

SEMM conducted the fieldwork, data management, and analysis and drafted the manuscript. CAS and MRH conceived of and helped to design the study. JM helped to develop and contributed to the data analysis. All the authors contributed to drafting the manuscript and approved the final manuscript.

\section{Acknowledgements}

We thank all the staff and students at the Centre for Sustainable Tropical Fisheries and Aquaculture including Fernanda de Faria, Vinay Udaywer, Mario Espinoza, Madeline Green, Lauren Meyer, and Jonathan Smart and countless volunteers for their help and support of this project. Primary financial support for acoustic tracking came from the National Environmental Research Project which was awarded to MRH and CAS. SEMM was also supported by an International Student Postgraduate Research Scholarship funded by the Australian Institute for Marine Science (AIMS) AIMS@JCU programme. Additional support was provided by James Cook University's School of Earth and Environmental Science (SEES).

\section{Author details}

1AIMS@JCU, Australian Institute of Marine Science and College of Marine and Environmental Science, James Cook University, Townsville, QLD 4811,

Australia. ${ }^{2}$ Centre for Sustainable Tropical Fisheries and Aquaculture and the College of Marine and Environmental Science, James Cook University, Townsville, QLD 4811, Australia. ${ }^{3}$ College of Marine and Environmental Science, James Cook University, Townsville, QLD 4811, Australia. ${ }^{4}$ Australian Institute of Marine Science, Townsville, QLD 4810, Australia. 
Received: 14 October 2014 Accepted: 11 March 2015

Published online: 27 April 2015

\section{References}

1. Beck MW, Heck KL, Able KW, Childers DL, Eggleston DB, Gillanders BM, et al. The identification, conservation, and management of estuarine and marine nurseries for fish and invertebrates. Bioscience. 2001;51:633-41.

2. Robertson Al, Duke NC. Mangroves as nursery sites: comparisons of the abundance and species composition of fish and crustaceans in mangroves and other nearshore habitats in tropical Australia. Mar Biol. 1987;96:193-205.

3. Heupel MR, Carlson JK, Simpfendorfer CA. Shark nursery areas: concepts, definition, characterization and assumptions. Mar Ecol Prog Ser. 2007;337:287-97.

4. Knip DM, Heupel MR, Simpfendorfer CA. Sharks in nearshore environments: models, importance, and consequences. Mar Ecol Prog Ser. 2010;402:1-11.

5. Suchanek TH. Temperate coastal marine communities: biodiversity and threats. Am Zool. 1994;34:100-14.

6. Lotze HK, Lenihan HS, Bourque BJ, Bradbury RH, Cooke RG, Kay MC, et al. Depletion, degradation, and recovery potential of estuaries and coastal seas. Science. 2006;312:1806-9.

7. Shahidul Islam M, Tanaka M. Impacts of pollution on coastal and marine ecosystems including coastal and marine fisheries and approach for management: a review and synthesis. Marine Pollut Bull. 2004;48:624-49.

8. Blaber SJM, Cyrus DP, Albaret J-J, Ching CV, Day JW, Elliott M, et al. Effects of fishing on the structure and functioning of estuarine and nearshore ecosystems. ICES J Mar Sci: J du Conseil. 2000;57:590-602.

9. Harley CDG, Randall Hughes A, Hultgren KM, Miner BG, Sorte CJB, Thornber CS, et al. The impacts of climate change in coastal Rechisky E, Wetherbee B: short-term movements of juvenile and neonate sandbar sharks, Carcharhinus plumbeus, on their nursery grounds in Delaware Bay. Environ Biol Fish. 2003;68:113-28.

10. Rechisky E, Wetherbee B. Short-term movements of juvenile and neonate sandbar sharks, Carcharhinus plumbeus, on their nursery grounds in Delaware Bay. Environ Biol Fish. 2003;68:113-28.

11. DiGirolamo AL, Gruber SH, Pomory C, Bennett WA. Diel temperature patterns of juvenile lemon sharks Negaprion brevirostris, in a shallow-water nursery. J Fish Biol. 2012:80:1436-48.

12. Ortega LA, Heupel MR, Van Beynen P, Motta PJ. Movement patterns and water quality preferences of juvenile bull sharks (Carcharhinus leucas) in a Florida estuary. Environ Biol Fish. 2009;84:361-73.

13. Branstetter S. Early life-history implications of selected carcharhinoid and lamnoid sharks of the northwest Atlantic. NOAA Tech Rep NMFS. 1990;90:17-28.

14. Castro J. The shark nursery of Bulls Bay, South Carolina, with a review of the shark nurseries of the southeastern coast of the United States. In: Demski L, Wourms J, editors. The reproduction and development of sharks, skates, rays and ratfishes. Netherlands: Springer; 1993. p. 37-48.

15. Knip DM, Heupel MR, Simpfendorfer CA, Tobin AJ, Moloney J. Ontogenetic shifts in movement and habitat use of juvenile pigeye sharks Carcharhinus amboinensis in a tropical nearshore region. Mar Ecol Prog Ser. 2011:425:233-46.

16. Feldheim KA, Gruber SH, Ashley MV. The breeding biology of lemon sharks at a tropical nursery lagoon. P Roy Soc Lond B Bio. 2002;269:1655-61.

17. Grubbs RD. Ontogenetic shifts in movements and habitat use. In: Carrier JC, Musick JA, Heithaus MR, editors. Sharks and their relatives II: biodiversity, adaptive physiology, and conservation. Boca Raton, FL: CRC Press; 2010. p. 319-42.

18. Carlson J, Heupel M, Bethea D, Hollensead L. Coastal habitat use and residency of juvenile Atlantic sharpnose sharks (Rhizoprionodon terraenovae). Estuar Coast. 2008;31:931-40

19. Munroe SEM, Simpfendorfer CA, Heupel MR. Habitat and space use of an abundant nearshore shark: Rhizoprionodon taylori. Mar Freshw Res. 2014;65:959-68.

20. Lyle J. Observations on the biology of Carcharhinus cautus (Whitley), C. melanopterus (Quoy \& Gaimard) and C. fitzroyensis (Whitley) from Northern Australia. Mar Freshw Res. 1987;38:701-10.

21. Simpfendorfer C, Chidlow J, McAuley R, Unsworth P. Age and growth of the whiskery shark, Furgaleus macki, from southwestern Australia. Environ Biol Fish. 2000:58:335-43.

22. Knip DM, Heupel MR, Simpfendorfer CA. Habitat use and spatial segregation of adult spottail sharks Carcharhinus sorrah in tropical nearshore waters. J Fish Biol. 2012;80:767-84.
23. Yates PM, Heupel MR, Tobin AJ, Moore SK, Simpfendorfer C. Diversity in shark nursery areas along a tropical coastline. Mar Freshw Res. 2015. doi:10.1071/MF14033.

24. Last PR, Stevens JD. Sharks and rays of Australia. 2nd ed. Victoria, Australia: CSIRO Publishing Collingwood; 2009.

25. Smart JJ, Harry AV, Tobin AJ, Simpfendorfer CA. Overcoming the constraints of low sample sizes to produce age and growth data for rare or threatened sharks. Aquat Conserv. 2013;23:124-34.

26. Harry AV, Tobin AJ, Simpfendorfer CA, Welch DJ, Mapleston A, White J, et al. Evaluating catch and mitigating risk in a multispecies, tropical, inshore shark fishery within the Great Barrier Reef World Heritage Area. Mar Freshw Res. 2011;62:710-21.

27. Espinoza M, Farrugia TJ, Lowe CG. Habitat use, movements and site fidelity of the gray smooth-hound shark (Mustelus californicus Gill 1863) in a newly restored southern California estuary. J Exp Mar Biol Ecol. 2011;401:63-74.

28. Ebert DA. Sharks, rays and chimaeras of California. Berkeley, CA: University California Press; 2003

29. Knip DM, Heupel MR, Simpfendorfer CA. To roam or to home: site fidelity in a tropical coastal shark. Mar Biol. 2012;159:1647-57.

30. Heupel MR, Yeiser BG, Collins AB, Ortega L, Simpfendorfer CA. Long-term presence and movement patterns of juvenile bull sharks, Carcharhinus leucas, in an estuarine river system. Mar Freshw Res. 2010;61:1-10.

31. Murchie K, Schwager E, Cooke S, Danylchuk A, Danylchuk S, Goldberg T, et al. Spatial ecology of juvenile lemon sharks (Negaprion brevirostris) in tidal creeks and coastal waters of Eleuthera, The Bahamas. Environ Biol Fish. 2010;89:95-104.

32. Castro Jl. The shark nursery of Bulls Bay, South Carolina, with a review of the shark nurseries of the southeastern coast of the United States. Environ Biol Fish. 1993;38:37-48.

33. Lowe CG. Bioenergetics of free-ranging juvenile scalloped hammerhead sharks (Sphyrna lewini) in Kāne'ohe Bay, Ō'ahu, HI. J Exp Mar Biol Ecol. 2002:278:141-56

34. Bush A, Holland K. Food limitation in a nursery area: estimates of daily ration in juvenile scalloped hammerheads, Sphyrna lewini (Griffith and Smith, 1834) in Kāne'ohe Bay, Ō'ahu, Hawai'í. J Exp Mar Biol Ecol. 2002:278:157-78

35. Edgar GJ, Shaw C. The production and trophic ecology of shallow-water fish assemblages in southern Australia III: general relationships between sediments, seagrasses, invertebrates and fishes. J Exp Mar Biol Ecol. 1995;194:107-31.

36. Jackson EL, Rowden AA, Attrill MJ, Bossley SJ, Jones MB. The importance of seagrass beds as a habitat for fisheries species. Oceanogr Mar Biol Annu Rev. 2001;39:269-303.

37. Orth R, Heck K, van Montfrans J. Faunal communities in seagrass beds: a review of the influence of plant structure and prey characteristics on predator-prey relationships. Estuaries. 1984;7:339-50.

38. Kuba M, Byrne R, Burghardt $G$. A new method for studying problem solving and tool use in stingrays (Potamotrygon castexi). Anim Cogn. 2010;13:507-13.

39. Schluessel V. Who would have thought that 'Jaws' also has brains? Cognitive functions in elasmobranchs. Anim Cogn. 2014;18:1-19.

40. Last PR. Freshwater and estuarine elasmobranchs of Australia. Sabah, Malaysia: Elasmobranch biodiversity, conservation and management: Proceedings of the International Seminar and Workshop; 1997.

41. Great Barrier Reef Marine Park Authority. A vulnerability assessment for the Great Barrier Reef: seagrass. In: A vulnerability assessment for the Great Barrier Reef: seagrass. Great Barrier Reef Marine Park Authority; 2011. http:// www.gbrmpa.gov.au/managing-the-reef/threats-to-the-reef/climate-change/ how-climate-change-can-affect-the-reef/great-barrier-reef-vulnerabilityassessment. Accessed 20 Apr 2014

42. Furnas MM. Catchments and corals: terrestrial runoff to the Great Barrier Reef. Australian Institute of Marine Science \& CRC Reef Research Centre; 2003. http://epubs.aims.gov.au/handle/1 1068/6477. Accessed 7 June 2014.

43. Chin A, Tobin AJ, Heupel MR, Simpfendorfer CA. Population structure and residency patterns of the blacktip reef shark (Carcharhinus melanopterus) in turbid coastal environments. J Fish Biol. 2013:82:1192-210.

44. Morrissey JF, Gruber SH. Habitat selection by juvenile lemon sharks, Negaprion brevirostris. Environ Biol Fish. 1993;38:311-9.

45. Collins AB, Heupel MR, Motta PJ. Residence and movement patterns of cownose rays Rhinoptera bonasus within a south-west Florida estuary. J Fish Biol. 2007:71:1159-78. 
46. Seagrass Watch. Seagrass Watch: Townsville. 2013. http://www.seagrass watch.org/townsville.html. Accessed 31 Dec 2014.

47. Cartamil DP, Vaudo JJ, Lowe CG, Wetherbee BM, Holland KN. Diel movement patterns of the Hawaiian stingray, Dasyatis lata: implications for ecological interactions between sympatric elasmobranch species. Mar Biol. 2003;142:841-7.

48. Sundstrom LF, Gruber SH, Clermont SM, Correia JPS, de Marignac JRC, Morrissey JF, et al. Review of elasmobranch behavioral studies using ultrasonic telemetry with special reference to the lemon shark, Negaprion brevirostris, around Bimini Islands, Bahamas. Environ Biol Fish. 2001;60:225-50.

49. Garla R, Chapman D, Wetherbee B, Shivji M. Movement patterns of young Caribbean reef sharks, Carcharhinus perezi, at Fernando de Noronha Archipelago, Brazil: the potential of marine protected areas for conservation of a nursery ground. Mar Biol. 2006;149:189-99.

50. Erftemeijer PLA, Robin Lewis lii R. Environmental impacts of dredging on seagrasses: a review. Mar Pollut Bull. 2006;52:1553-72.

51. Walker DI, McComb AJ. Seagrass degradation in Australian coastal waters. Mar Poll Bull. 1992;25:191-5.

52. Ralph P, Tomasko D, Moore K, Seddon S, Macinnis-Ng CO. Human impacts on seagrasses: eutrophication, sedimentation, and contamination. In: Seagrasses: biology, ecology, and conservation. Netherlands: Springer; 2006. p. 567-93.

53. McGlathery KJ. Macroalgal blooms contribute to the decline of seagrass in nutrient-enriched coastal waters. J Phycol. 2001;37:453-6.

54. Haynes D, Müller J, Carter S. Pesticide and herbicide residues in sediments and seagrasses from the Great Barrier Reef World Heritage Area and Queensland coast. Mar Pollut Bull. 2000;41:279-87.

55. Orth RJ, Carruthers TJB, Dennison WC, Duarte CM, Fourqurean JW, Heck KL, et al. A global crisis for seagrass ecosystems. Bioscience. 2006:56:987-96.

56. Waycott M, Duarte CM, Carruthers TJB, Orth RJ, Dennison WC, Olyarnik S, et al. Accelerating loss of seagrasses across the globe threatens coastal ecosystems. Proc Natl Acad Sci U S A. 2009;106:12377-81.

57. Hughes AR, Williams SL, Duarte CM, Heck KL, Waycott M. Associations of concern: declining seagrasses and threatened dependent species. Front Ecol Environ. 2008;7:242-6.

58. Kessel ST, Cooke SJ, Heupel MR, Hussey NE, Simpfendorfer CA, Vagle S, et al. A review of detection range testing in aquatic passive acoustic telemetry studies. Rev Fish Biol Fisheries. 2014;24:199-218. doi:10.1007/s11160-013-9328-4.

59. Abecasis D, Erzini K. Site fidelity and movements of gilthead sea bream (Sparus aurata) in a coastal lagoon (Ria Formosa, Portugal). Estuar Coast Shelf Sci. 2008;79:758-63.

60. Werry JM, Planes S, Berumen ML, Lee KA, Braun CD, Clua E. Reef-fidelity and migration of tiger sharks, Galeocerdo cuvier, across the Coral Sea. PLoS One. 2014;9:e83249.

61. Simpfendorfer CA, Heupel MR, Hueter RE. Estimation of short-term centers of activity from an array of omnidirectional hydrophones and its use in studying animal movements. Can J Fish Aquat Sci. 2002;59:23-32.

62. Calenge $\mathrm{C}$. The package adehabitat for the $\mathrm{R}$ software: a tool for the analysis of space and habitat use by animals. Ecol Model. 2006:197:516-9.

63. Pinheiro J, Bates D, DebRoy S, Sarkar D. nlme: linear and nonlinear mixed effects models. R package version 3.1-109; 2013. http://cran.r-project.org/ web/packages/nlme/index.html. Accessed 5 May 2014.

64. Wagenmakers E-J, Farrell S. AIC model selection using Akaike weights. Psychon B Rev. 2004;11:192-6.

65. Strauss RE. Reliability estimates for IVlev's electivity index, the forge ratio, and a proposed linear index of food selection. T Am Fish Soc. 1979;108:344-52

66. Hutchinson G. Concluding remarks. In: Whittaker R, Stroudsburg LS, editors. Niche: theory and application. Pennsylvania: Dowden: Hutchinson and Ross, Inc.; 1957. p. 387-99.

67. Devictor V, Clavel J, Julliard R, Lavergne S, Mouillot D, Thuiller W, et al. Defining and measuring ecological specialization. J Appl Ecol. 2010;47:15-25.

68. Smith EP. Niche breadth, resource availability, and inference. Ecology. 1982;63:1675-81.

69. Arlettaz R. Habitat selection as a major resource partitioning mechanism between the two sympatric sibling bat species Myotis myotis and Myotis blythii. J Anim Ecol. 1999;68:460-71.

\section{Submit your next manuscript to BioMed Central and take full advantage of:}

- Convenient online submission

- Thorough peer review

- No space constraints or color figure charges

- Immediate publication on acceptance

- Inclusion in PubMed, CAS, Scopus and Google Scholar

- Research which is freely available for redistribution

Submit your manuscript at www.biomedcentral.com/submit 